\title{
Measured Interfacial Residual Strains Produced by In-Flight Ice
}

\author{
Andrew Work ${ }^{1}$, Jonathan Salem² Eric Baker $^{3}$, Ernestina Schirmer ${ }^{4}$, Rebekah Douglass ${ }^{5}$, Richard \\ Kreeger $^{2}$ \\ ${ }^{1}$ Ohio Aerospace Institute ${ }^{2}$ NASA Glenn Research Center ${ }^{3}$ Connecticut Reserve Technologies ${ }^{4}$ Purdue University ${ }^{5}$ Penn State \\ University
}

\begin{abstract}
The formation of ice on aircraft is a highly dynamic process during which ice will expand and contract upon freezing and undergoing changes in temperature. Finite element analysis (FEA) simulations were performed investigating the stress/strain response of an idealized ice sample bonded to an acrylic substrate subjected to a uniform temperature change. The FEA predictions were used to guide the placement of strain gages on custom-built acrylic and aluminum specimens. Tee rosettes were placed in two configurations adjacent to thermocouple sensors. The specimens were then placed in icing conditions such that ice was grown on top of the specimen. It was hypothesized that the ice would expand on freezing and contract as the temperature of the interface returned to the equilibrium conditions. While results from the aluminum specimens matched this hypothesis, results from the acrylic specimens show a short period of contraction followed by a much larger expansion at the interface, indicating more complex ice growth thermodynamics than anticipated. Some samples were observed to delaminate, suggesting that the residual strain is significant to the shedding of ice for inflight applications.
\end{abstract}

\section{Introduction}

The formation of ice during in-flight conditions is a highly complex process capable of producing highly variable geometry at the microand macro-scales. During typical in-flight icing, an aircraft will encounter water droplets in clouds which are super-cooled below freezing to the ambient temperature. These droplets strike the aircraft where the momentum of the droplet is sufficient to penetrate the aerodynamic boundary layer around the aircraft structure, and freeze (partially or completely) on impact. Ice is commonly observed to form in or between the two categories of glaze and rime ice. Rime ice is characterized as being opaque and producing a geometric shape conformal to the aircraft wing, while glaze is characterized as being transparent and producing highly variable shapes including horns on straight airfoils, or scallops on swept airfoils. In a glaze-ice event, a water layer forms over solid ice, where the ice grows outward from the aircraft structure. As the ice grows, the aerodynamics and thermodynamics evolve as the growing ice produces an increasingly large aerodynamic disturbance, and provides insulation between the affected surface and the ambient air. The ice is expected to expand upon freezing, and the interfacial temperature is expected to decline in a return to the ambient temperature as ice builds [1]. It was hypothesized that the residual stresses in the ice will initially be in compression as the ice tends to expand (ideally putting the strain gage in tension), and then should decrease, gradually transitioning to tension as the ice contracts with declining temperature (putting the strain gage in compression).

While thermodynamic characterization of the ice has been studied extensively for the purpose of characterizing the growth of the ice [25], challenges still remain. For example, the dynamic temperature profile is ice is largely unknown and the ice-water interface cannot currently be modeled in sufficient detail to determine local flow as grains form. Further, the mechanical stresses formed in the ice as a result of the formation process have been largely ignored by literature, especially with regards to adhesion measurement [6]. During data collection for a recent study, several observations were made indicating that residual stresses may play a significant role in the removal of ice from aircraft structures $[1,7]$. Work et. al. observed ice falling off of stainless steel samples, and reported lower adhesion strengths at lower temperatures speculating damage to the samples from residual stresses and coupon mounts. Since samples were observed to delaminate spontaneously prior to damage from the mounting mechanism, residual strain in the ice are expected to be capable of producing stresses at the interface of similar magnitude to the adhesive strength under certain conditions. The following study was performed to investigate and document these strains in support of the recent effort at the NASA Glenn Research Center (GRC) to study the adhesive strength of ice. Residual stress at the interface is expected to strongly affect the adhesion and shedding characteristics of ice, since these stresses will superpose the stresses known to cause shedding. Residual stresses may result in earlier shedding if the stresses tend to weaken the interface, or may result in delayed shedding if the interface is put into compression.

\section{Experimental Design}

\section{Strain Gage Placement}

In order to optimally place strain gages on the acrylic and aluminum substrates, a finite element analysis (FEA) simulation was performed to investigate the interface stress and strain state for a simplified case. The study was performed in COMSOL Multiphysics ${ }^{\circledR}$, where idealized samples were modeled as two 2 " long beams with 0.25 " square profiles, bonded together along the beam length. The entire model was then subjected to a constant temperature change, $\Delta \mathrm{T}=-10$ ${ }^{\circ} \mathrm{C}$, and the equilibrium strains were predicted (see Figure 1-Figure 4). The acrylic specimen is on the bottom and the ice is on the top in Figure 1 and Figure 2.

Page 1 of 8 


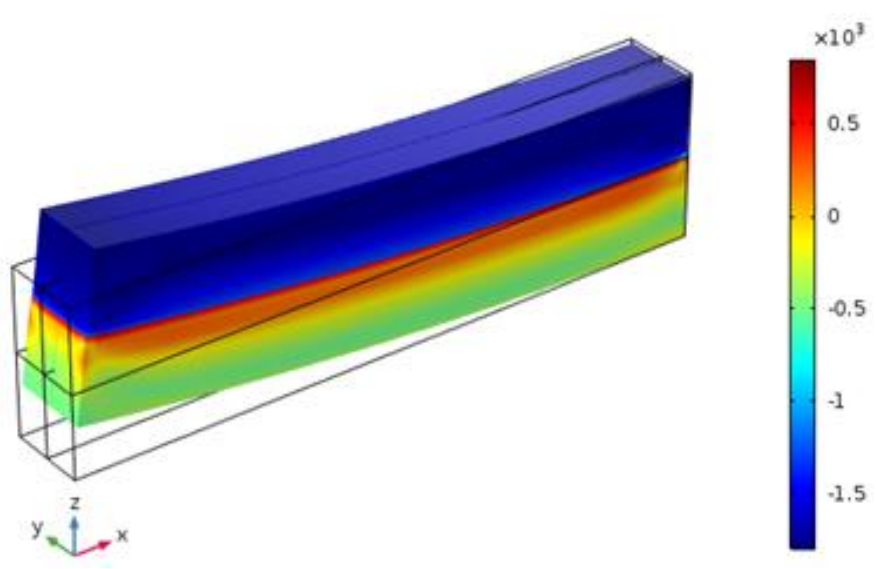

Figure 1. First principal strain $\varepsilon_{\mathrm{p} 1}(\mu \varepsilon)$. Deformation scale factor 20x. $\Delta \mathrm{T}=-10$ ${ }^{\circ} \mathrm{C}$.

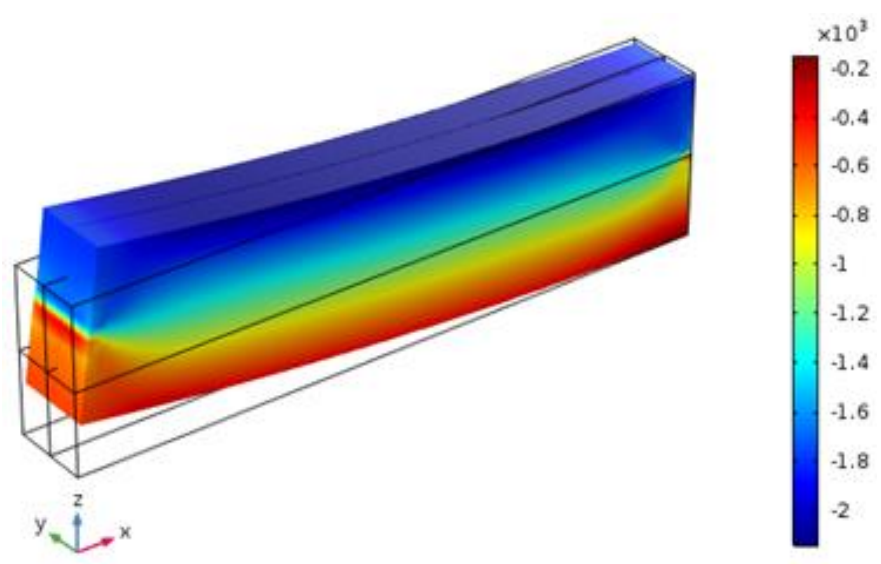

Figure 2. Axial strain $\varepsilon_{x x}(\mu \varepsilon)$. Deformation scale factor $20 \mathrm{x} . \Delta \mathrm{T}=-10^{\circ} \mathrm{C}$.

The higher coefficient of thermal expansion for ice resulted in the beam bending toward the ice, causing the entire specimen to contract. Plots of the strain components along the centerline of the interface are shown in Figure 3, with the first principal strain denoted as $\varepsilon_{\mathrm{p} 1}$. The strain was most uniform in the center of the sample, which was used to determine the strain gage placement on the samples. The stress through the center of the specimen, along the $\mathrm{Z}$ axis, is shown in Figure 4. The ice was predicted to be in tensile stress near the interface and compressive stress away from the interface.

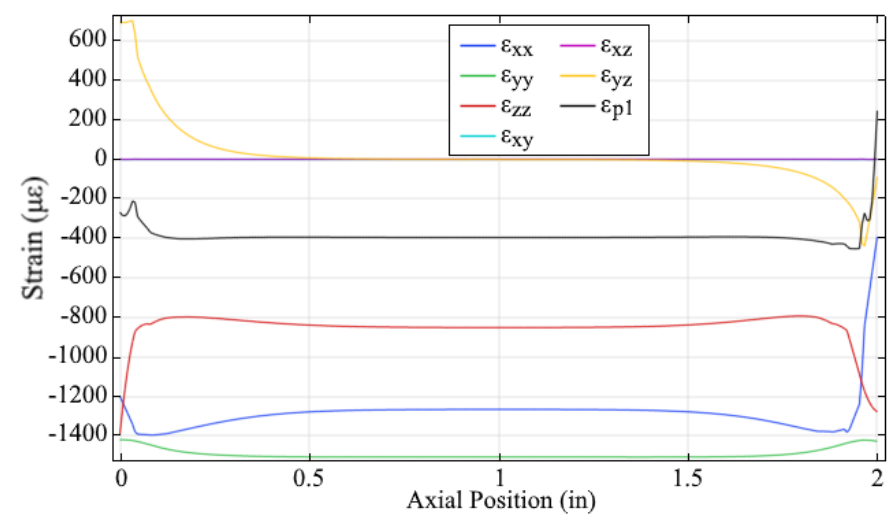

Figure 3. Strains along the center of the ice/acrylic sample along the long axis. $\Delta \mathrm{T}=-10^{\circ} \mathrm{C}$.

Page 2 of 8

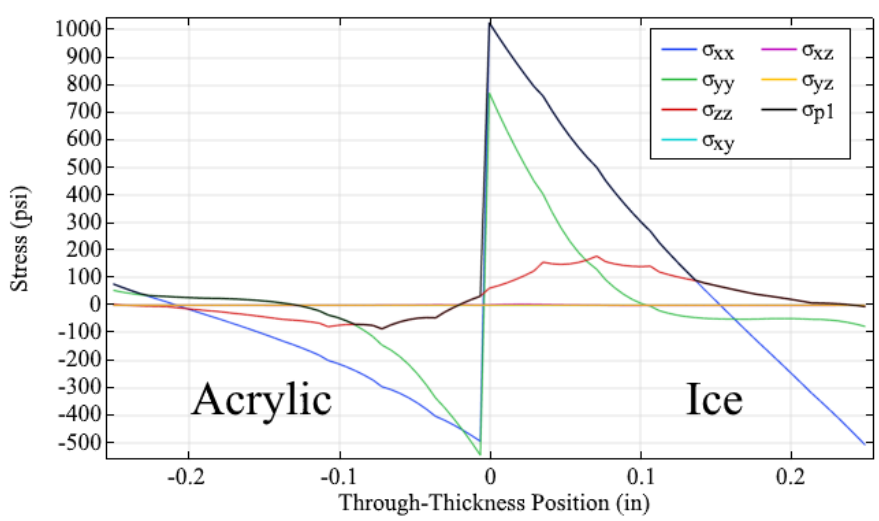

Figure 4. Predicted stress along $\mathrm{Z}$ axis at center of specimen.

\section{IRT Test Matrix}

Strain measurements were taken as part of two IRT tests, which were conducted in July and November 2018. The first test, conducted in July, utilized acrylic specimens. Only one run from this test is reported (run AQ). Data from all runs in the second test (November) are reported. In the second test, the objective was to obtain samples and data for a velocity sweep at two different temperatures using aluminum specimens, and verify the function of new mounts. The IRT test matrices for runs with reported data are shown in Table 1.

Table 1. IRT test parameters.

\begin{tabular}{c|cccccc} 
Run & $\begin{array}{c}V \\
(\mathrm{kts})\end{array}$ & $\begin{array}{c}T_{s} \\
\left({ }^{\circ} \mathrm{C}\right)\end{array}$ & $\begin{array}{c}T_{t} \\
\left({ }^{\circ} \mathrm{C}\right)\end{array}$ & $\begin{array}{c}L W C \\
\left(\mathrm{~g} / \mathrm{m}^{3}\right)\end{array}$ & $\begin{array}{c}M V D \\
(\mu \mathrm{m})\end{array}$ & $\begin{array}{c}\text { Time } \\
(\mathrm{s})\end{array}$ \\
\hline$A Q$ & 200 & -15.2 & -10.0 & 0.65 & 20 & 219.4 \\
$B A$ & 100 & -21.3 & -20.0 & 0.50 & 20 & 476.4 \\
$B B$ & 125 & -22.0 & -20.0 & 0.50 & 20 & 362.9 \\
$B C$ & 150 & -22.9 & -20.0 & 0.50 & 20 & 299.3 \\
$B D$ & 175 & -24.0 & -20.0 & 0.50 & 20 & 241.5 \\
$B E$ & 200 & -25.1 & -20.0 & 0.50 & 20 & 241.4 \\
$B F$ & 150 & -17.9 & -15.0 & 0.50 & 20 & 296.9 \\
$B G$ & 100 & -16.3 & -15.0 & 0.50 & 20 & 396.6 \\
$B H$ & 125 & -17.0 & -15.0 & 0.50 & 20 & 476.5 \\
$B I$ & 175 & -19.0 & -15.0 & 0.50 & 20 & 253.9 \\
$B J$ & 200 & -20.2 & -15.0 & 0.50 & 20 & 223.1 \\
$B K$ & 150 & -17.9 & -15.0 & 0.50 & 20 & 301.1
\end{tabular}

\section{Mounting and Geometry}

In the previous effort to study the adhesion of ice, rectangular samples were produced from 17-4 PH steel, and were 2 inches in length, and 0.25 inches in width and depth $[1,7]$. Dovetail slots were cut into the back of the coupons for mounting in the Icing Research Tunnel (IRT) at GRC. In this current study, six samples were modified such that cuboid specimens were mounted on top of each of the previously machined stainless steel coupons, fastened at one end with a flat-head screw. This mounting scheme allowed the beam to expand and contract on top of the stainless steel base, and reduced variability due to the dovetail mounting mechanism. Mounts were 
numbered left to right, top to bottom looking downstream, in eight columns and six rows (prior tests only used four columns $[1,7]$ ).

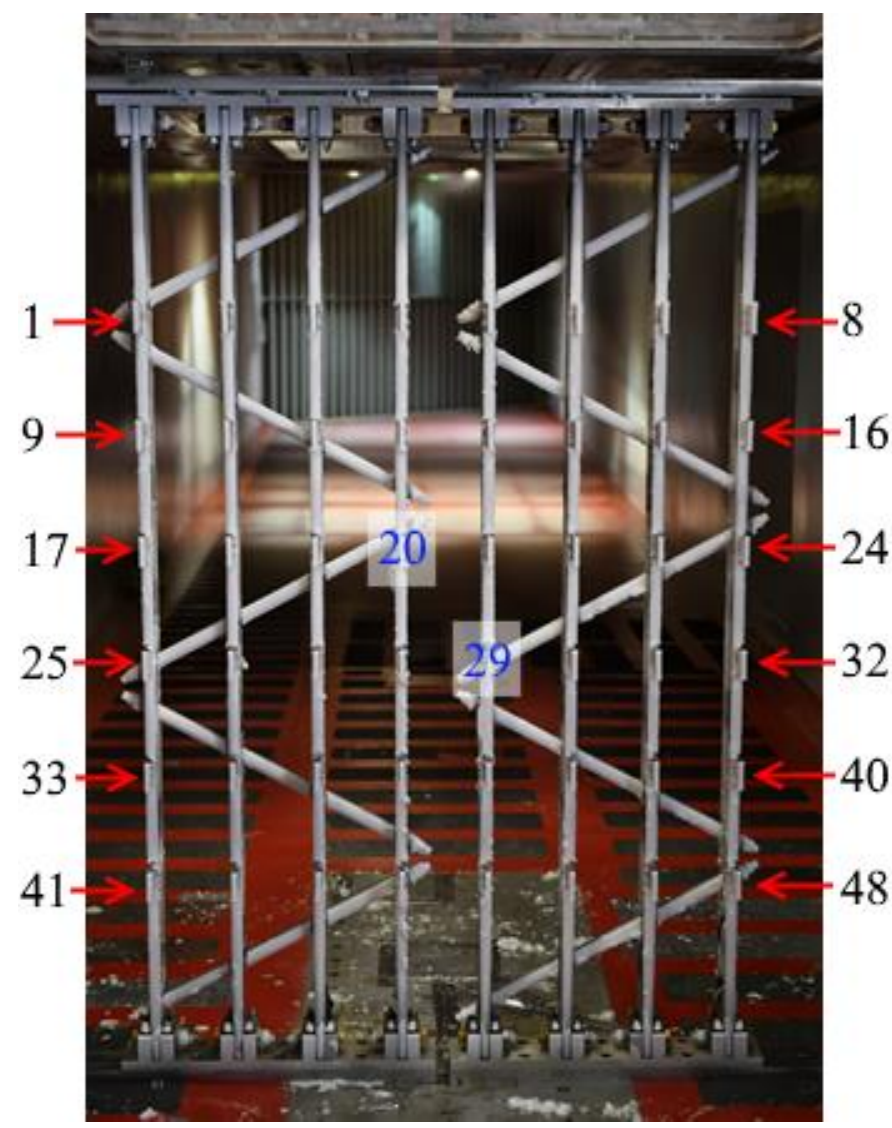

Figure 5. XT model after run BD with first and last column mount numbers labeled. Mount 20 and 29 labels overlaid.

Two coupons were used simultaneously in the IRT in mount positions 20 and 29. K-type thermocouples (TCs) were used to measure the temperature through the IRT facility data acquisition system. Foil and welded TCs were placed next to the strain gage rosettes with one of three mounting procedures. These were as follows: 1) foil TCs were mounted with the same methodology that was used for the strain gages [8], 2) weldable TCs were mounted using an epoxy, and 3) foil TCs were mounted in Polyimide tape and glued to the surface. The coupons with the foil-mount TCs were used initially since they more accurately matched the thermodynamics of the strain gages since they had similar thickness and the same glue and polyurethane coating, while the epoxied samples were used as spares. Several gages broke during use, and so some runs do not have data for each axial and transverse gage. The mount details, specimen material, gain, and excitation voltage are shown in Table 2.
Table 2. Specimen number (SN), mount number, gage location, TC mounting type, material, runs, amplifier gain, and excitation voltage.

\begin{tabular}{c|ccccccc} 
SN & $\begin{array}{c}\text { Mount } \\
\text { Location }\end{array}$ & $\begin{array}{c}\text { Gage } \\
\text { Loc. }\end{array}$ & $\begin{array}{c}\text { TC } \\
\text { Type }\end{array}$ & Mat'l & Runs & $\begin{array}{c}\text { Amp. } \\
\text { Gain }\end{array}$ & $\begin{array}{c}\text { Exc. } \\
(\text { V) }\end{array}$ \\
\hline 1 & 29 & Front & 1 & Acrylic & AN-AR & 500 & 10 \\
2 & & Back & 1 & Acrylic & & & \\
3 & & Front & 2 & Acrylic & & & \\
4 & 20 & Back & 2 & Acrylic & AN-AR & 500 & 10 \\
5 & 20 & Front & 3 & 6061 & BA-BF & 200 & 8 \\
6 & 29 & Front & 3 & 6061 & BA-BK & 200 & 8
\end{tabular}

The specimens were 2 inches long, 0.25 inches wide, and 0.15 inches thick. An acrylic specimen is shown on an original mount in Figure 6, and an aluminum specimen is shown on an updated mount in Figure 7. The placement of the screw mount at the end of the sample allowed the C2A-06-062LT-350 tee rosette strain gages to be placed in the center of the specimens, which were mounted using MicroMeasurements recommended procedure [8].

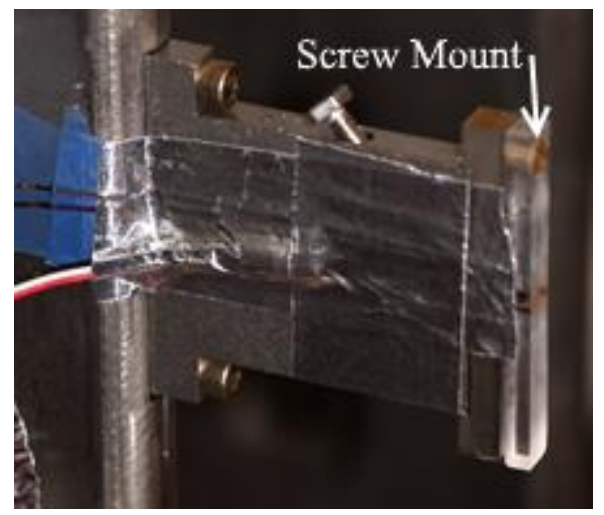

Figure 6. Specimen \#4 prior to the first spray. Original Mounting Configuration with acrylic specimen.

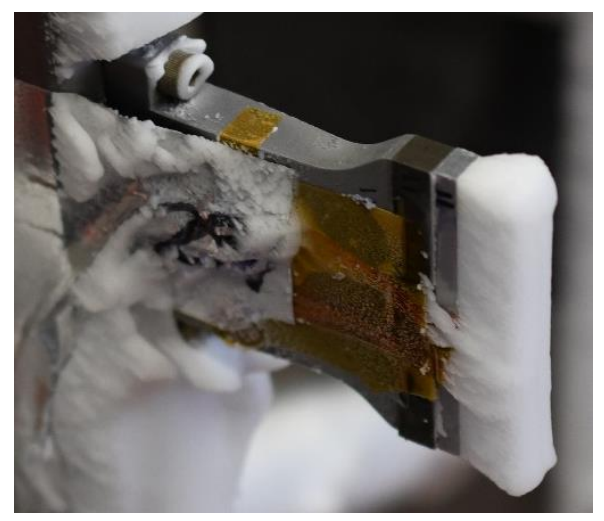

Figure 7. Specimen \#6 after run BB. Updated Mounting Configuration.

\section{Temperature Correction}

The TC data was used to correct the thermal output of the strain gage using the procedure provided by the manufacturer [9]. However, suitable gages that were matched to acrylic or aluminum were not available in time for the test, but rosettes were available that were calibrated to stainless steel surfaces. The provided thermal output curves accounted for the effect of the thermal expansion of steel. The 
Coefficient of Thermal Expansion (CTE) that the gages were calibrated for was subtracted from the results in order to get the actual strain at the ice-specimen interface. In order to verify this, specimen 3 was placed in an environmental chamber. As a comparison, a CEA-13-250UN-350 gage (compensated to aluminum 2024-T4) was mounted on a 17-4 stainless steel coupon and placed next to the acrylic specimen. A thermistor probe was used to measure the temperature of the air next to the sample, and the sample was allowed to equilibrate at the set temperature until a steady-state strain was observed. Uncorrected strain measurements are shown by the filled-in data points in Figure 8.

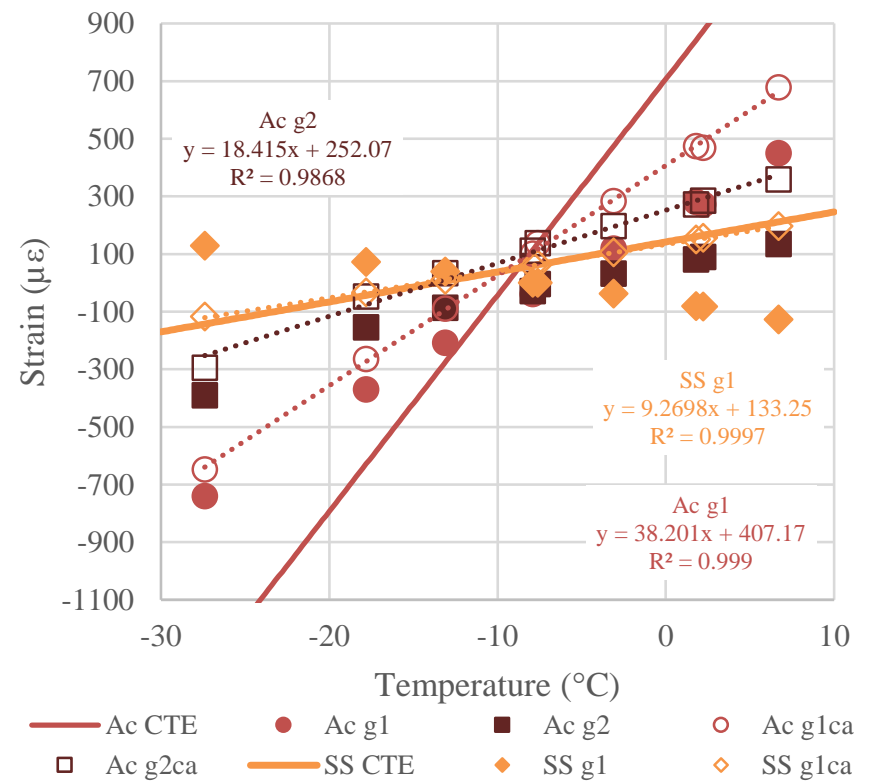

Figure 8 . Thermal output measurements compared to linear plots of the coefficient of thermal expansion. Fit lines shown with dotted lines.

For the acrylic data, a nominal value of $75 \mu \mathrm{m} / \mathrm{m} * \mathrm{~K}$ was used to plot the Acrylic thermal expansion data ("Ac CTE" in Figure 8). A nominal value of $10.8 \mu \mathrm{m} / \mathrm{m} * \mathrm{~K}$ was used to plot the stainless steel thermal expansion data ("SS CTE" in Figure 8). The measured data on the stainless steel and acrylic samples were corrected by subtracting the expected thermally induced strain from the thermal output correction, using a value of $10.8 \mu \mathrm{m} / \mathrm{m} * \mathrm{~K}$ for the rosette mounted to the acrylic sample (manufacturer compensated to 1018 steel), and a value of $21.1 \mu \mathrm{m} / \mathrm{m} * \mathrm{~K}$ for the gage mounted to the $17-4$ sample (manufacturer compensated to 2024-T4 aluminum). The corrected data was fit and the slope was determined to compare to the nominal values. The fit value for steel came in relatively close at $14 \%$ below the nominal value, though the value for acrylic varied by position on the rosette and was $49 \%$ lower for the axial gage (g1), and $75 \%$ lower for the transverse gage (g2). The cause of the observed anisotropy in the acrylic was unknown, but possibly due to the placement of the epoxy close to the gage location or texture within the acrylic due to stretching during production. The disagreement between measured data and recorded data was the reason that the specimen material was switched to aluminum for the second IRT test. The discussion presented will center on the data collected during the second IRT test.

There is no ideal way to perform a temperature correction on the gages in the IRT since the substrate experienced a dynamic temperature gradient. However, the temperature correction was performed with and without the thermal expansion of the substrate material removed to show the difference. The temperature correction was performed by following the method prescribed in TN504-1 [9], Page 4 of 8 as with the data above, and subtracting the thermal expansion for steel $(10.8 \mu \mathrm{m} / \mathrm{mK})$ since the gages were designed to be used on steel parts. Data corrected in this manner was given a "cb" suffix in legend entries. Data was additionally corrected by adding the coefficient of thermal expansion for aluminum $(22.1 \mu \mathrm{m} / \mathrm{mK})$ back into the correction; data corrected in this manner was given a "ca" suffix in legend entries. The legend numbers and letters correspond to the mount number, the axis ( $\mathrm{g} 1$ for axial, g2 for transverse), and the temperature correction ("ca" or "cb"), respectively. The acrylic specimen data was thermally corrected in the same manner as the aluminum specimen data, except that the "ca" data used a nominal CTE of $70 \mu \mathrm{m} / \mathrm{mK}$ for acrylic[10]. The thermocouples were listed as TC with the mount number following. For example, mount 29 transverse gage with correction to aluminum is listed as " $29 \mathrm{~g} 1 \mathrm{ca}$ ".

\section{Results \& Discussion}

Data was obtained in most runs by allowing the tunnel to come up to speed and zeroing each strain channel, and starting the data recording seconds before the cloud turned on. An exception to this was made for the last run (BK), in which the data collection was initiated before the tunnel fan was activated. Run BK was a repeat of run BF. The thermocouples were only activated during the spray of the cloud, preventing temperature correction from being performed on pre- and post-test data. The correction without accounting for the CTE of aluminum was relatively small, and so this data closely followed the raw data. In all cases, the same temperature correction was used for each gage (axial and transverse), so the difference between the two readings did not change with temperature correction. The data for run BF is shown in Figure 9.

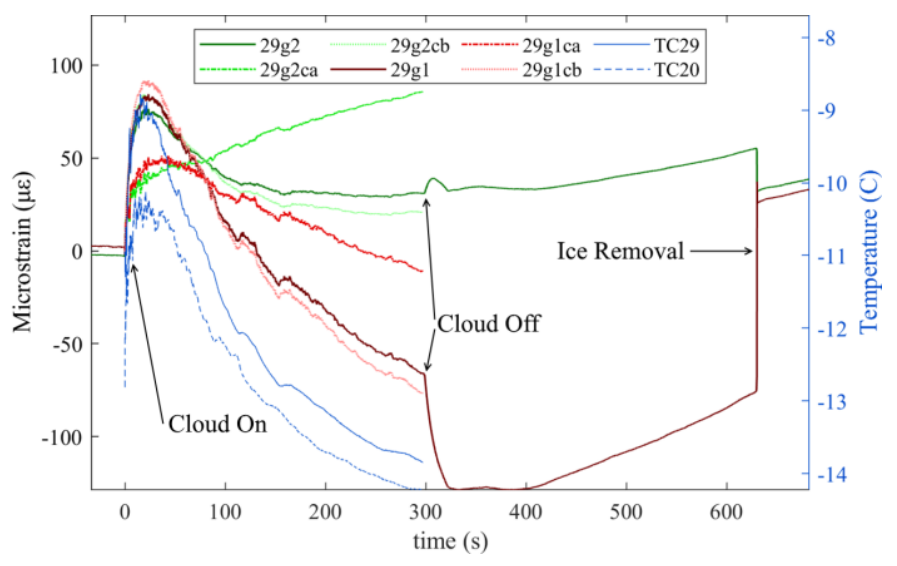

Figure 9. Run BF data. Axial gage is denoted by "g1", transverse by "g2".

The raw strain gage data was re-zeroed at the time of cloud on in post-processing. Prior to this point, there was a small offset in the strain reading from the axial and transverse gage that disappeared as soon as the cloud was turned on. Once the droplets in the cloud hit the sample, rapid heating (due to the latent heat of the water) and expansion was observed. In all runs, this observed expansion at the interface was followed by compression, which was markedly more significant on the axial gage than the transverse gage. The observed compression corresponded with a decrease in temperature at the interface during the spray. In run $\mathrm{BF}$, the two gage readings diverge rapidly. A sharp decrease in the strain from the axial gage was observed in all data as soon as the cloud was turned off, which was accompanied by a small increase in the transverse gage data. This was likely due to rapid cooling of the ice since the outer interface was 
no longer being held close to the melting point by the latent heat of the impinging droplets. The difference in the transverse gage data and the axial gage data suggests a Poisson effect, probably due to the entire sample flexing as the outer layer of ice cooled. Once the cloud was turned off, the fan was powered down. Once the tunnel was safe to enter, photographic documentation of the test was obtained, and then the ice was removed by hand from mounts 20 and 29. The removal by hand was recorded, showing a vertical line in the data. The data from run BK is shown in Figure 10.

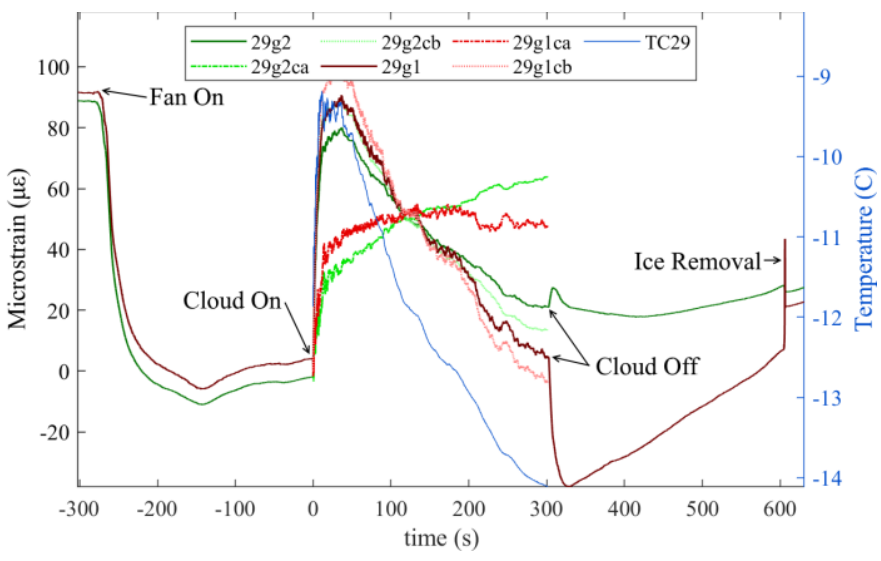

Figure 10. Run BK data. Axial gage is denoted by "g1", transverse by "g2".

In run $\mathrm{BK}$, the data was recorded before the fan was activated, but still re-zeroed at cloud on. The decrease in strain that was observed when the fan was activated was due to a decrease in the temperature of the samples. Interestingly, the peak strain after the cloud was turned on was similar in magnitude to the strain recorded with the fan off. The features observed in run BF were also observed in BK, however several key differences should be noted. First, the minimum uncorrected axial strain observed in BK was $-38.1 \mu \varepsilon$ compared to $128 \mu \varepsilon$ for $\mathrm{BF}$, though the maximum strain was similar $(90.7 \mu \varepsilon$ for $\mathrm{BK}, 84.4 \mu \varepsilon$ for $\mathrm{BF}$ ). The difference in strain between axial and transverse gages was much less significant in BK than in BF $(-16.6 \mu \varepsilon$ and $-96.6 \mu \varepsilon$, respectively). Finally, the difference in pre- and postbreak axial strain was much smaller in BK than in BF $(13.5 \mu \varepsilon$ and $101 \mu \varepsilon$, respectively).

The difference between runs BF and BK was likely due to the samples in runs BG-BK partially delaminating during the spray. It was noted that samples from runs BG-BK fell off of coupons in the tunnel during the removal process, whereas samples from runs BA$\mathrm{BF}$ were robust - no samples from these runs spontaneously delaminated. From the samples that did delaminate in BK, marks were observed on the ice (on the delaminated interface) similar to those observed in prior studies [1]. These marks were likely due to the presence of a small air gap between the warmer ice and colder aluminum specimen, where the ice sublimated and frost was deposited on the metal surface. The delamination likely occurred after the maximum strain was observed, but before 100s into the spray where the axial and transverse data started to diverge in run $\mathrm{BF}$, but to a lesser extent in run BK.

The data was reduced by denoting the strains and times at each event: cloud on, maximum temperature (mount 29 TC), maximum axial strain, cloud off, transverse strain peak (following cloud off, not available for mount 20 data), axial gage local minimum (following cloud off), and pre- and post-break. Run BF produced data that fit poorly with the remaining runs, and was omitted from further

Page 5 of 8 analysis as an outlier in spite of the evidence suggesting that samples in the following runs were damaged. The data was averaged by temperature, and is depicted in Figure 11. In the first two runs (BA and $\mathrm{BB}$ ), the photographic documentation was slower and the delay to breaking the samples was much longer. These two runs were separated from the $\mathrm{T}_{\mathrm{t}}=-20{ }^{\circ} \mathrm{C}$ data and grouped together, and the remaining runs $(\mathrm{BC}-\mathrm{BE})$ were grouped together in Figure 12. The first two runs were denoted with a "2" following the temperature in the legend, and the remaining three were denoted with a " 3 ". The time in both figures was offset so that cloud off was at $0 \mathrm{~s}$.

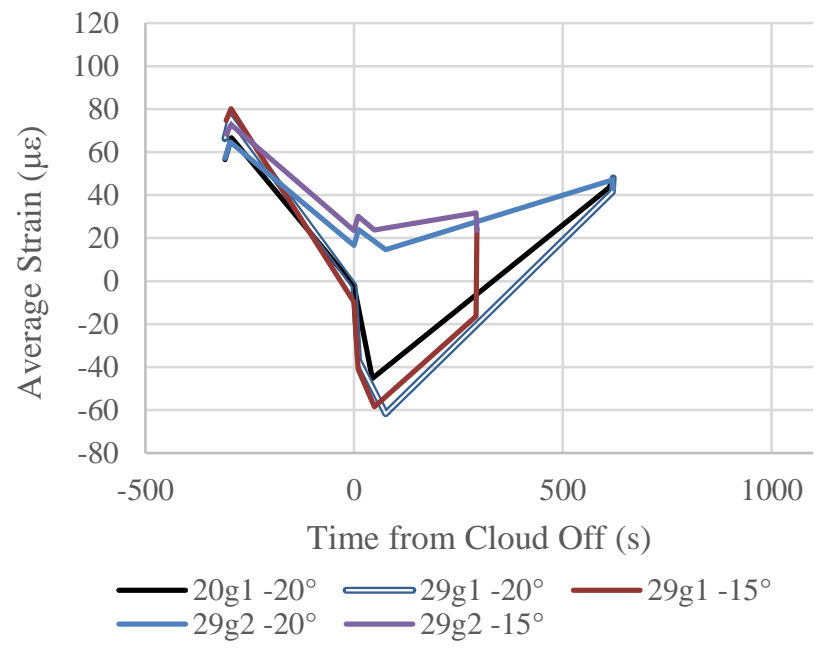

Figure 11. Strain averaged at tunnel events. Run BI excluded for first two values.
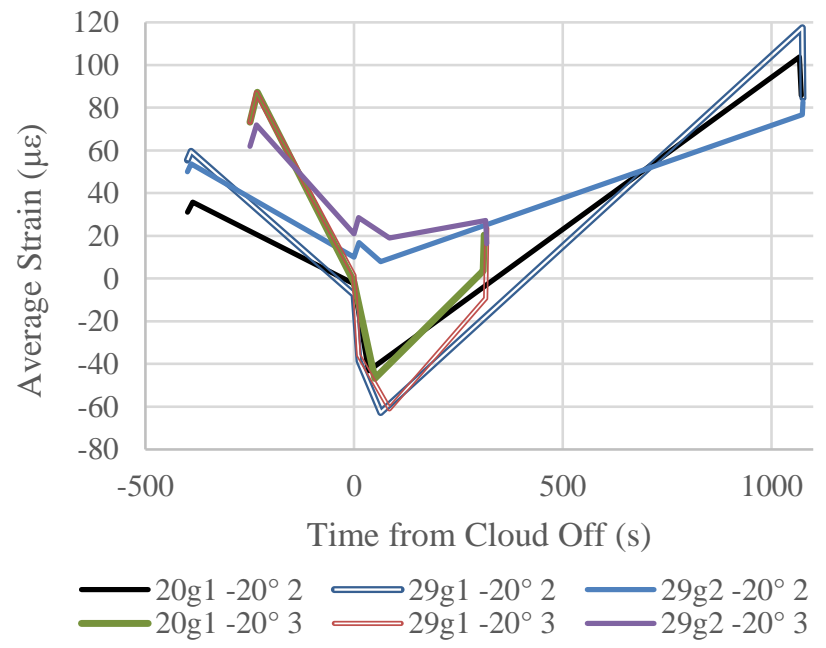

Figure 12. Strain averaged at tunnel events, runs BA-BB denoted with 2, runs BC-BE denoted with 3.

The data shows a consistent and significant deviation in the axial and transverse gages immediately following cloud off. The data was similar between runs, with small variations with temperature. The most significant difference in the $\mathrm{T}_{\mathrm{t}}=-15^{\circ} \mathrm{C}$ and the $\mathrm{T}_{\mathrm{t}}=-20^{\circ} \mathrm{C}$ data in Figure 11 was primarily due to the longer delay between the cloud off event and the removal of ice from the sample in runs BA and BB, which is shown by separating those two runs from the $\mathrm{T}_{t}=-20^{\circ} \mathrm{C}$ data as in Figure 12. The data for the remaining runs (labeled with the "3" suffix in Figure 12) line up closely with the $\mathrm{T}_{\mathrm{t}}=-15^{\circ} \mathrm{C}$ data in Figure 11, while the recorded strain in the first two runs cross in the 
axial and transverse direction just before the 700s mark. At the removal of ice, the transverse gage always had a more significant change than the axial gage, likely due to bending of the sample. The difference between the first two runs and the remaining eight (excluding BF) was likely due to the steady increase in temperature of the sample once the fan was turned off. The samples almost certainly enter storage in a state of stress. Past testing has shown that the measured adhesion strength of the samples typically double in strength as they were allowed to anneal for at least one month at the stagnation temperature [1].

The effect of velocity and temperature were also compared by taking the maximum, minimum, and average strain recorded at each event (listed above). For the average values, it is important to note that the mount 20 data was missing the transverse gage, so one event was removed from each average which will bias the mount 20 data to higher values. The mount 20 axial gage data is shown in Figure 13. The mount 29 axial data is shown in Figure 15, with the axial gage data on the left and the transverse gage data on the right.

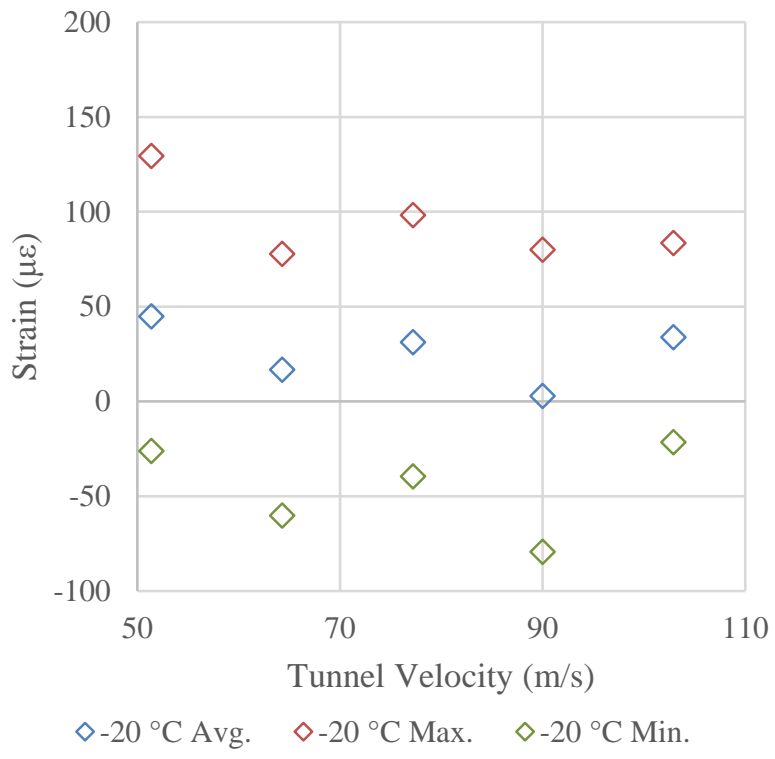

Figure 13. Mount 20 axial gage averaged event strain data.

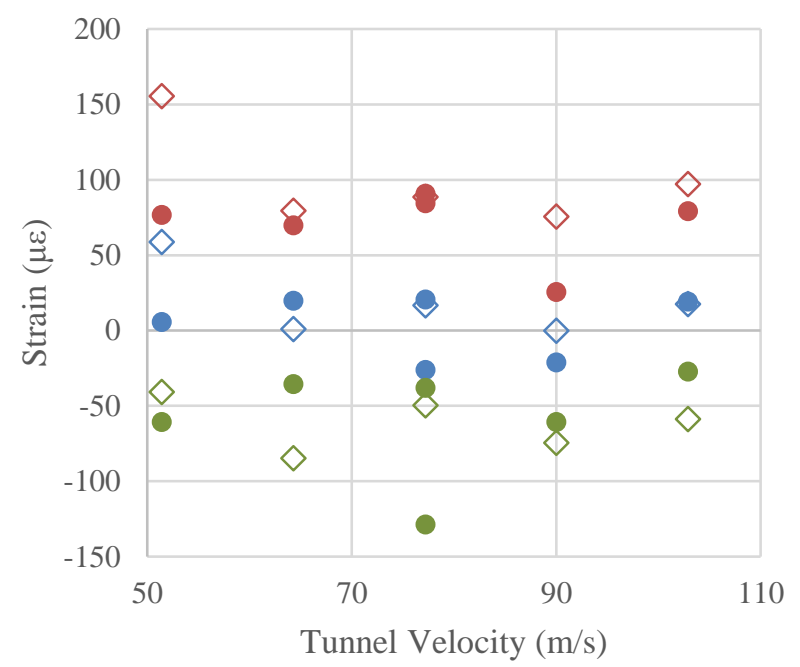
$\diamond-20{ }^{\circ} \mathrm{C}$ Avg.
$\diamond-20^{\circ} \mathrm{C}$ Max.
$\diamond-20{ }^{\circ} \mathrm{C}$ Min.
$-15{ }^{\circ} \mathrm{C}$ Avg.
- $15{ }^{\circ} \mathrm{C}$ Max.
๑ $-15{ }^{\circ} \mathrm{C}$ Min.

Figure 14. Mount 29 averaged event strain data from axial gage.

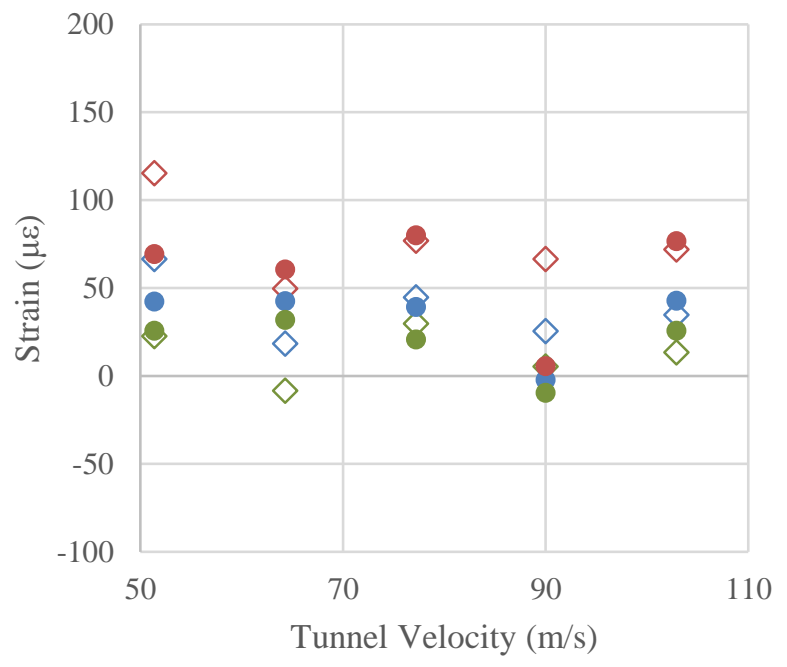

$$
\begin{array}{lll}
\diamond-20^{\circ} \mathrm{C} \text { Avg. } & \diamond-20^{\circ} \mathrm{C} \text { Max. } & \diamond-20^{\circ} \mathrm{C} \text { Min. } \\
\bullet-15^{\circ} \mathrm{C} \text { Avg. } & -15^{\circ} \mathrm{C} \text { Max. } & -15^{\circ} \mathrm{C} \text { Min. }
\end{array}
$$

Figure 15. Mount 29 averaged event strain data from transverse gage.

Between the three gages, no obvious relationship between velocity or temperature and strain was able to be determined. The variation in strain with the change in temperature and velocity was likely within the uncertainty of the test, which was not characterized. The uncertainty was affected by numerous factors, including the variability of the cloud, the uncertainty of the temperature readings (approximately $\pm 1{ }^{\circ} \mathrm{C}$ ) and the corresponding temperature correction, the uncertainty of the gage and measurement system, and other, unknown factors.

Data was also taken with acrylic specimens since the more compliant acrylic was expected to allow higher strains to be recorded, resulting in a more sensitive measurement. Unlike the data taken on aluminum specimens, the data for acrylic included temperature from the front (mount 29) and rear (mount 20) of the specimens, giving a more 
complete picture of the thermal state of the specimen during and shortly after the spray. Temperature data was recorded post spray in the first IRT test. Data from run AQ is shown in Figure 16.

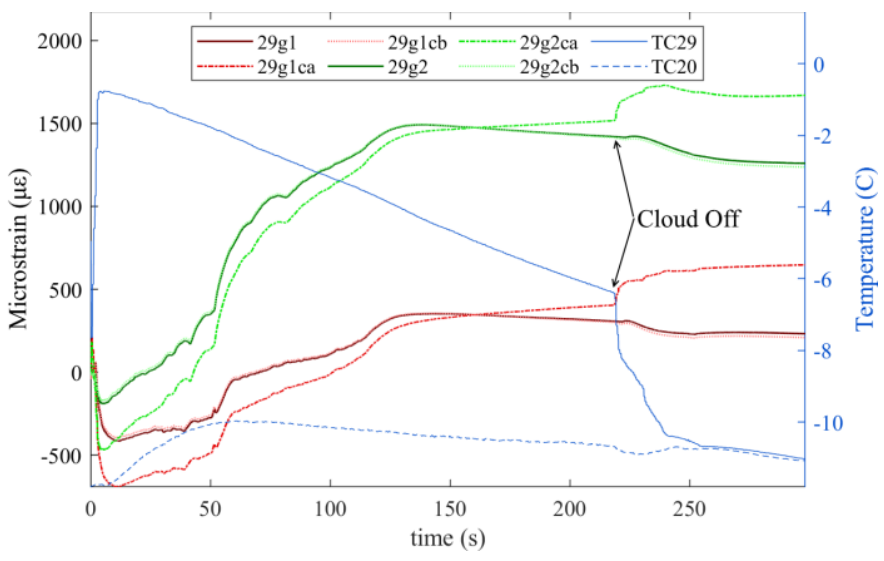

Figure 16. Data from run AQ, mount 29 (acrylic specimen).

Features observed in run AQ were typical for all runs with recorded data from the first IRT test. Time was offset such that the start of the spray was at 0s. The cloud off can be observed by a sharp drop in the surface temperature data (TC29) in Figure 16 around the 225s mark. The strain had a small local maximum close to $0 \mathrm{~s}$, after which it quickly dropped, hit a local minimum, and then rose to approximately $1500 \mu \varepsilon$. The aluminum specimens followed a nearly opposite pattern, in which the data rose quickly and dropped off, sometimes going negative. With the acrylic specimens, the transverse gage recorded the highest strains. While the acrylic specimen data was captured at a warmer temperature $\left(-10^{\circ} \mathrm{C}\right)$, this was unlikely to cause the difference in the pattern of strain observed since the temperature profile was similar between runs.

\section{Summary/Conclusions}

Aluminum and acrylic specimens were instrumented with strain gages and thermocouples. These specimens were then placed inside the IRT and a cloud was sprayed onto the samples to form ice. The strain and temperature response was recorded during the spray, and the strain response was recorded while the ice was removed. Temperature correction was performed on the strain data, however no suitable method was available to account for the effects of thermal expansion of the specimen due to the presence of a dynamic temperature gradient. The data shows that the state of stress in the samples was dynamic during and shortly after the spray in the IRT, and that removing the ice released strain on the samples. This was consistent with previous findings that the samples strengthened as they were allowed to anneal. The data did not correlate with temperature or wind tunnel velocity, though limited temperature data points were available. Samples taken at the warmer temperature likely delaminated during or shortly after the spray, resulting in higher minimum strain values recorded. The strains induced at the interface between the ice and the specimen were observed to change significantly with different specimen materials. Residual stresses play a significant role in the adhesion and shedding of in-flight ice, and must be accounted for in order to obtain accurate adhesion data.

\section{References}

1. Work, A., The Measurement of the Adhesion of Glaze Ice, in Mechanical Engineering. 2018, University of Louisville. p. 268.

2. Myers, T.G., Extension to the Messinger model for aircraft icing. AIAA journal, 2001. 39(2): p. 211-218.

3. Tsao, J.-C. and R.E. Kreeger, Evaluation of scaling methods for rotorcraft icing. 2010.

4. Tsao, J.-C. and S. Lee, Evaluation of Icing Scaling on Swept NACA 0012 Airfoil Models. 2012.

5. Messinger, B.L., Equilibrium temperature of an unheated icing surface as a function of air speed. Journal of the aeronautical sciences, 1953. 20(1): p. 29-42.

6. Work, A. and Y. Lian, A Critical Review of the Measurement of Ice Adhesion to Solid Substrates. Progress in Aerospace Sciences, 2018.

7. Work, A.H., et al. An Experimental Study of the Adhesion Strength of Impact Ice. in 2018 Atmospheric and Space Environments Conference. 2018.

8. Micro-Measurements, V., Surface preparation for strain gage bonding, in $B$ 129-8 Surface Preparation for Strain Gage Bonding. 2014. p. 1-7.

9. Micro-Measurements, V., TN-504-1 Strain gage thermal output and gage factor variation with temperature, in Tech Note. 2014. p. 35-47.

10. ToolBox, E. Coefficients of Linear Thermal Expansion. [cited 2018 08/15/2018]; Available from: https://www.engineeringtoolbox.com/linearexpansion-coefficients-d_95.html.

\section{Contact Information}

Corresponding Author: Andrew Work, andrew.h.work@nasa.gov

\section{Acknowledgments}

The authors would like to acknowledge the support of the IRT staff. The authors would also like to thank the Revolutionary Vertical Lift Technology and Advanced Air Transport Technology projects for their funding support. 


\section{Definitions/Abbreviations}

Ac Acrylic

ca Temperature correction including subtraction of substrate thermal expansion

cb

Temperature correction without subtraction of substrate thermal expansion

CTE Coefficient of Thermal Expansion

FEA Finite Element Analysis

g1 Gage 1, axial gage in $\mathrm{x}$ direction

g2 Gage 2, transverse gage in y direction

GRC Glenn Research Center

IRT Icing Research Tunnel

LWC Liquid Water Content

MVD Median Volumetric Diameter

SN Specimen Number
Stainless Steel

TC Thermocouple

$\mathbf{T}_{\mathbf{s}} \quad$ Static Temperature in IRT

$\mathbf{T}_{\mathbf{t}} \quad$ Total Temperature in IRT

V Velocity in IRT

$\boldsymbol{\varepsilon}_{\mathbf{p} 1} \quad$ First principal strain

$\boldsymbol{\varepsilon}_{\mathrm{xx}} \quad$ Strain in $\mathrm{x}$ direction

$\boldsymbol{\varepsilon}_{\mathrm{xy}} \quad$ Shear strain in xy plane

$\boldsymbol{\varepsilon}_{\mathrm{xz}} \quad$ Shear strain in xz plane

$\boldsymbol{\varepsilon}_{\mathbf{y y}} \quad$ Strain in y direction

$\varepsilon_{\mathrm{yz}} \quad$ Shear strain in yz plane

$\varepsilon_{\mathrm{zz}} \quad$ Strain in $\mathrm{z}$ direction 